\title{
PERANCANGAN APLIKASI POS PADA MUTIARA LAUNDRY DENGAN MENGIMPLEMENTASIKAN BAHASA PEMROGRAMAN JAVA
}

\author{
Lydia Agustin ${ }^{1}$, Muhammad Soleh Ritonga ${ }^{2}$ \\ ${ }^{1,2}$ Universitas Indraprasta PGRI \\ Jl. Raya Tengah Gedong, Kec. Ps. Rebo, Kota Jakarta Timur, \\ 11ydiaagustin.lydia@gmail.com, 2soleh_0502@yahoo.com
}

\begin{abstract}
ABSTRAK
Bisnis laundry merupakan bisnis kecil memiliki banyak peminat juga memiliki peluang pasar yang cukup besar sehingga bisnis dapat cepat berkembang dan dirasa akan lebih mudah jika dimasukan unsur teknologi dan informasi didalamnya. Pada saat ini Mutiara laundy masih menggunakan sistem manual dalam pencatatannya, seperti dalam hal pencatatan keuangan dan pencatatan transaksinya masih menggunakan buku. Tujuan dalam penelitian ini yaitu memudahkan para pegawai dalam melakukan proses transaksi, membuat laporan hasil transaksi, pendataan setiap karyawan, petugas dan harga. Metodologi penelitian yang penulis gunakan dalam sistem pengolahan data yaitu teknik pengumpulan data dengan wawancara oleh pihak terkait dan mendokumentasikan informasi yang dibutuhkan. Selain itu, Penulis melakukan berbagai macam penelitian dengan menggunakan metode kepustakaan yang sangat relevan dalam masalah sistem informasi. Setelah melakukan penelitian, menganalisa permasalahan yang terjadi dan menyelesaikan masalah tersebut, maka penulis dapat menyimpulkan bahwa, Aplikasi Point Of Sales pada Mutiara Laundry memberikan kemudahan kepada kasir untuk melaporkan laporan data pelanggan, data pegawai, data harga kepada pemilik laundry serta mempermudah proses transaksi dengan sistem.
\end{abstract}

Kata Kunci: Aplikasi, Point Of Sales, Java

\section{ABSTRACT}

The laundry business is a small business that has many enthusiasts and also has a large enough market opportunity so that the business can quickly develop and it is felt that it will be easier if it is incorporated into the elements of technology and information in it. At this time Mutiara Laundry still uses a manual system in its records, such as in terms of financial records and records still using books. The purpose of this research is to make it easier for employees to process transactions, make reports on transaction results, collect data for each employee, officer and price. The author's research methodology In the data processing system, this study uses a data collection methodology by interviewing related parties and documenting the required information. In addition, the author conducted various kinds of research using library methods that are very relevant in information systems problems. After doing research, analyzing the problems that occur and solving these problems, the authors can conclude that, the Point Of Sales application at Mutiara Laundry makes it easy to report customer data reports, employee data, laundry owner price data and ease of transaction processing with the system.

Key Word: Application, Point Of Sales, Java

\section{PENDAHULUAN}

Manusia pada masa ini tidak bisa terlepas dari teknologi, karena hampir seluruh bidang pekerjaan manusia sudah dimasuki oleh teknologi. Menurut UU No.12 tahun 2002, teknologi merupakan cara atau metode dan proses, atau produk yang dihasilkan dari pemanfaatan berbagai disiplin ilmu pengetahuan yang menghasilkan nilai bagi pemenuhan kebutuhan, kelangsungan dan peningkatan mutu kehidupan manusia(Chandra, 2019).

Banyak orang yang sibuk akan kegiatannya dan sulit membagi waktu untuk mengerjakan pekerjaan rumah dan pekerjaan kantor sekaligus 
sehingga dibutuhkan program untuk membantu menyelesaikan pekerjaan dengan efisien. Dengan demikian hadirlah bisnis jasa laundry untuk membantu menyelesaikan pekerjaan rumah seperti dalam hal urusan pakaian karena bagi sebagian orang pakaian yang menumpuk merupakan suatu masalah. Mutiara laundry merupakan usaha yang bergerak dibidang jasa, jumlah transaksi perharinya juga cukup banyak, tetapi Mutiara laundry masih menggunakan pencatatan manual didalamnya sehingga nenakan waktu dalam melayani transaksi dan pencatatan keuangan.

Bisnis laundry merupakan bisnis kecil memiliki banyak peminat juga memiliki peluang pasar yang cukup besar sehingga bisnis dapat cepat berkembang dan dirasa akan lebih mudah jika dimasukan unsur teknologi dan informasi. Pada saat ini Mutiara laundy masih menggunakan sistem manual dalam pencatatannya, seperti dalam hal pencatatan keuangan dan pencatatan transaksinya masih menggunakan buku, oleh karena itu dengan aplikasi Point of sales pada Mutiara Laundry hal-hal yang bersifat manual dapat dilakukan secara komputerisasi, sehingga proses pencatatan akan lebih efisien, dan cepat. Berdasarkan hal tersebut muncullah ide untuk membuat aplikasi sistem kasir laundry yang digunakan oleh kasir untuk mencatat data dan mempermudah dalam proses transaksi. Aplikasi ini diharapkan dapat membantu menjalankan bisnis laundry secara efisien dan membantu admin dalam pengolahan data.

"Perancangan sistem merupakan tahap setelah analisis sistem, di mana pada perancangan sistem digambarkan sistem yang akan dibangun sebelum dilakukan pengcodingan kedalam bahasa pemrograman."(Sidharta \& Wati, 2015) "Sistem dapat didefinisaikan sebagai kumpulan dari elemen-elemen berupa data, jaringan kerja dari prosedur-prosedur yang saling berhubungan, sumber daya manusia, teknologi hardware maupun software yang saling berinteraksi sebagai satu kesatuan untuk mencapai tujuan/sasaran tertentu yang sama."(Hamidin \& Maniah, 2017)
"P.O.S atau Point of Sales merupakan sistem pencatatan proses jual beli yang terjadi disuatu perusahaan, untuk membantu proses transaksi. POS juga dapat diartikan sebagai check-out counter dan cash register. Sistem informasi menyediakan kebutuhan pengolahan data transaksi harian yang mendukung fungsi operasi organisasi untuk menyimpan, mengambil, mengubah dan mengolah informasi yang diterima."(Afrianto et al., 2020)

"Laundry adalah jasa binatu dengan biaya jasa yang kompetitif dan terjangkau. Bisnis laundry ini dirasa menguntungkan karena banyak orang yang tidak sempat mencuci pakaian sendiri dan juga bagi yang tidak mempunyai banyak waktu (pekerja) atau sebagian besar adalah mahasiswa."(Manik \& Nusantara, 2019)

Bahasa pemrograman pada aplikasi ini menggunakan bahasa pemrograman Java dengan menggunakan aplikasi Netbeans dan aplikasi ini menggunakan $M y S Q L$ sebagai database untuk penyimpana data.

"Java merupakan bahasa pemrograman yang bersifat umum, dan khusus didesain untuk memanfaatkan dependensi implementasi seminimal mungkin. Karena kemampuannya untuk memungkinkan aplikasi Java berjalan Beberapa platform sistem operasi yang berbeda"(Rusli et al., 2016)

"Netbeans merupakan sebuah aplikasi Integrated Development Environment (IDE) yang berbasiskan Java dari Sun Microsistems yang berjalan diatas swing dan banyak digunakan sekarang sebagai editor untuk berbagai bahasa pemrograman."(Nofriadi, 2018)

"MySQL adalah DBMS open source dengan dua bentuk lisensi, yaitu Free Software (perangkat lunak bebas) dan Shareware (perangkat lunak berpemilik yang penggunaannya terbatas). Jadi $M y S Q L$ adalah server database gratis dengan lisensi GNU General Public License (GPL).”(Fitri, 2020) 
Berdasarkan pada permasalahan di atas, peneliti berupaya membuat aplikasi yang dapat mempermudah sistem kasir dan pendataan karyawan serta customer. Oleh karena itu peneliti menyusun penelitian berjudul: "Perancangan Aplikasi Point Of Sales pada Mutiara Laundry dengan Mengimplementasikan Bahasa Pemrograman Java."

Tujuan dari penelitian mengenai aplikasi sistem point of sales pada Mutiara Laundry adalah sebagai berikut: (1) Memberikan kemudahan kepada pegawai Mutiara laundry agar lebih efisien dan cepat dalam melakukan proses transaksi, (2) Memberikan kemudahan kepada kasir untuk melaporkan laporan data pelanggan, data pegawai, data harga kepada pemilik laundry, (3) Memberikan kemudahan kepada pegawai untuk melaporkan hasil transaksi dan laporan keungan kepada pemilik laundry.

Manfaat yang diharapkan dari penelitian yang telah dilakukan oleh peneliti adalah aplikasi ini dapat membantu proses transaksi agar lebih efisien, dapat mempermudah kasir dalam proses pendataan pengimputan data pelanggan, data pegawai, dan mempermudah kasir dalam proses pendataan pengimputan data pelanggan, data pegawai.

\section{METODE PENELITIAN}

Research and Development (R\&D) merupakan metode penelitian secara sengaja, sistematis, untuk menemukan, memperbaiki, mengembangkan, menghasilkan, maupun menguji keefektifan produk, model, maupun metode/ strategi/ cara yang lebih unggul, baru, efektif, efisien, produktif, dan bermakna(Putra, 2015).

Research and Development (R\&D) merupakan metode penelitian yang digunakan untuk menghasilkan produk tertentu dan menguji keefektifan produk tersebut(Sugiyono, 2016).

Dalam pelaksanaan penelitian pengembangan (R\&D) terdapat beberapa langkah yang akan dilakukan peneliti, peneliti akan menggunakan Model R \& D Borg and Gall ini terdiri dari sepuluh langkah pelaksanaan diantaranya (1) penelitian dan pengumpulan data (research and information collecting), (2) perencanaan (planning), (3) pengembangan draf produk (develop preliminary form of product), (4) uji coba lapangan (preliminary field testing), (5) penyempurnaan produk awal (main product revision), (6) uji coba lapangan (main field testing), (7) menyempurnakan produk hasil uji lapangan (operational product revision), (8) uji pelaksanaan lapangan (operational field testing), (9) penyempurnaan produk akhir (final product revision), dan (10) diseminasi dan implementasi (dissemination and implementation).

Dalam menyusunan penelitian ini, penulis mengambil objek pada Mutiara Laundry yang bertempat di daerah Jl. Duren Tiga Raya, RT.5/RW.6, Duren Tiga, Kec. Pancoran, Kota Jakarta Selatan, Daerah Khusus Ibukota Jakarta 12760.

Pengumpulan data yang digunakan adalah metode kualitatif dengan melakukan:

Observasi

Aktivitas terhadap suatu proses atau objek yang dimana dapat merasakan dan kemudian memahami pengetahuan tersebut dari sebuah fenomena yang ada berdasarkan pengetahuan dan gagasan yang sudah diketahui sebelumnya, selain itu untuk mendapatkan berbagai macam informasi yang dibutuhkan untuk melanjutkan suatu penelitian.

\section{Wawancara}

yaitu percakapan antara dua orang atau lebih secara langsung atau tatap muka antara narasumber dan pewawancara. Penulis melakukan wawancara secara lisan dan tatap muka dengan Pemilik Mutiara Laundry. Penulis melakukan wawancara pada:

Hari / Tanggal : Rabu, 3 Maret 2021

Tempat : Mutiara Laundry

Narasumber : Pemilik

a. Apakah dengan sistem transaksi manual yang sudah ada pada karyawan dapat bekerja dengan teliti dan efisien?

b. dalam proses berjalannya sistem dalam melakukan proses pengolahan data masihkah terjadi kerusakan data? 
c. Bagaimana data-data transaksi, data karyawan, data pelanggan dan data harga di simpan di mutiara laundry?

\section{HASIL DAN PEMBAHASAN}

Rancangan sistem yang diusulkan penulis ialah sebuah sistem komputerisasi dalam proses transaksi pada Mutiara Laundry dengan memudahkan dalam sistem transaksi, administrasi, pendataan dan laporan.

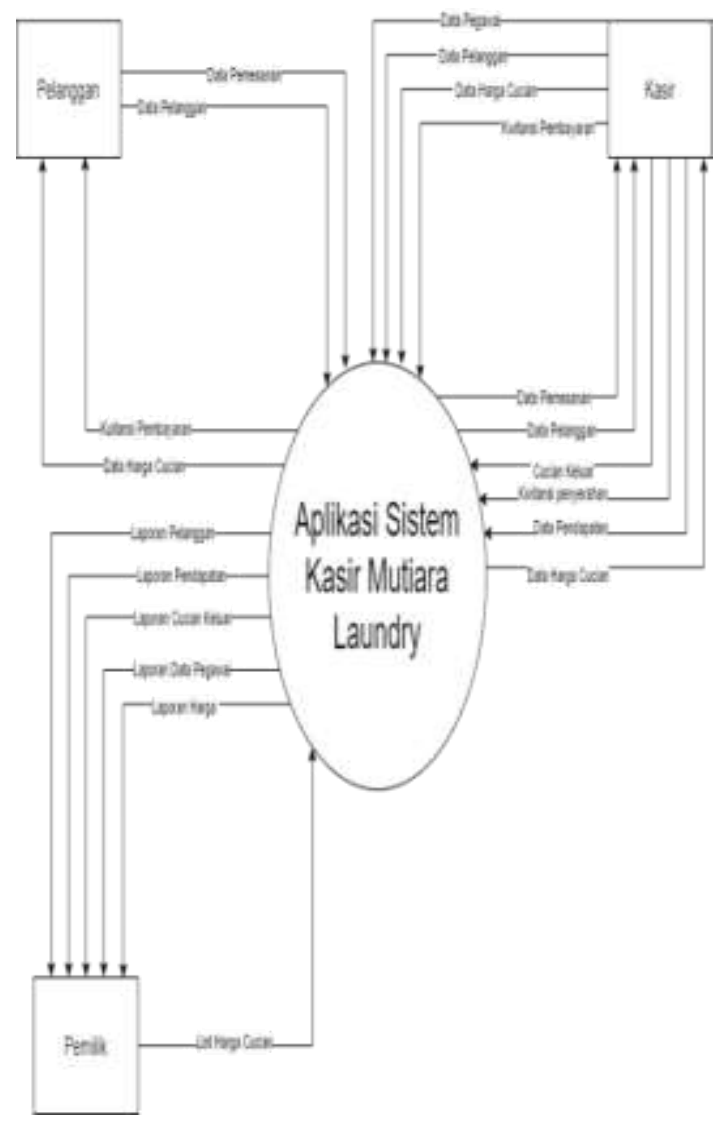

Gambar 1. Diagram Konteks yang Diusulkan

Pada diagram konteks terdapat alur sebuah sistem dari pelanggan hingga petugas.

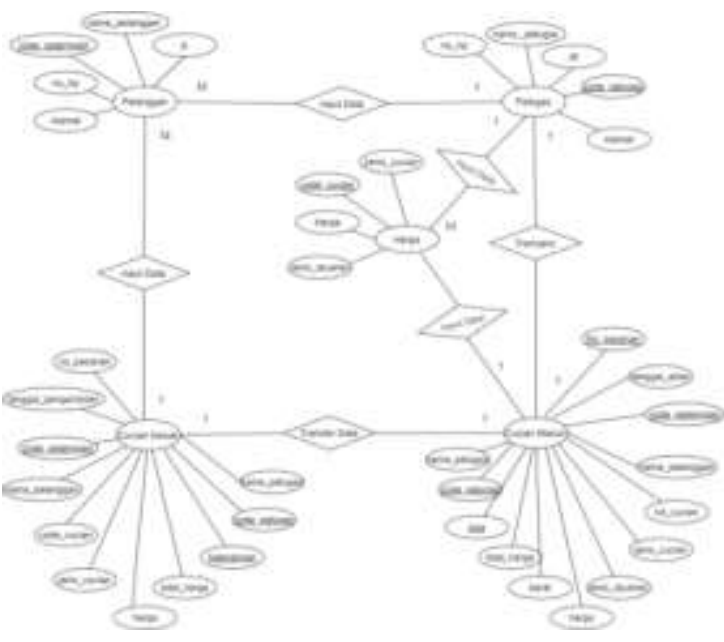

Gambar 2. ERD

Berikut gambaran alur pada sebuah sistem Point Of Sales pada Mutiara Laundry

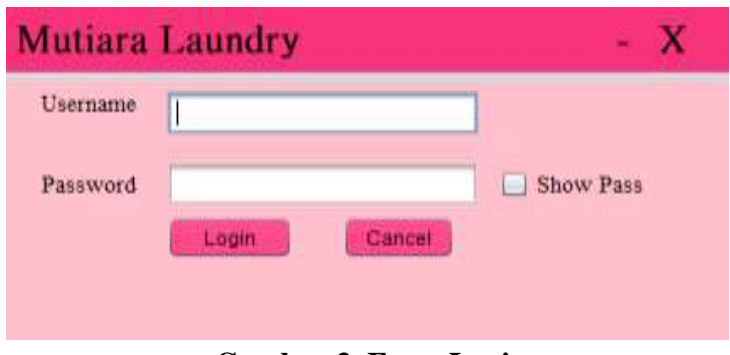

Gambar 3. Form Login

Tampilan ini terdapat pada awal program, tampilan menu Login digunakan sebagai katakunci sebelum kita memasuki program utama. Agar tidak ada orang lain yang dapat mengakses program ini, pengguna harus memasukan username dan password untuk dapat masuk ke program dan terdapat checkbox show pass berguna agar pelanggan dapat melihat password yang dimasukan untuk mengurangi kesalahan dalam memasukan password. Setelah pengguna sudah memasukan username dan password yang benar maka dapat klik login dan pengguna langsung masuk kedalam program. 


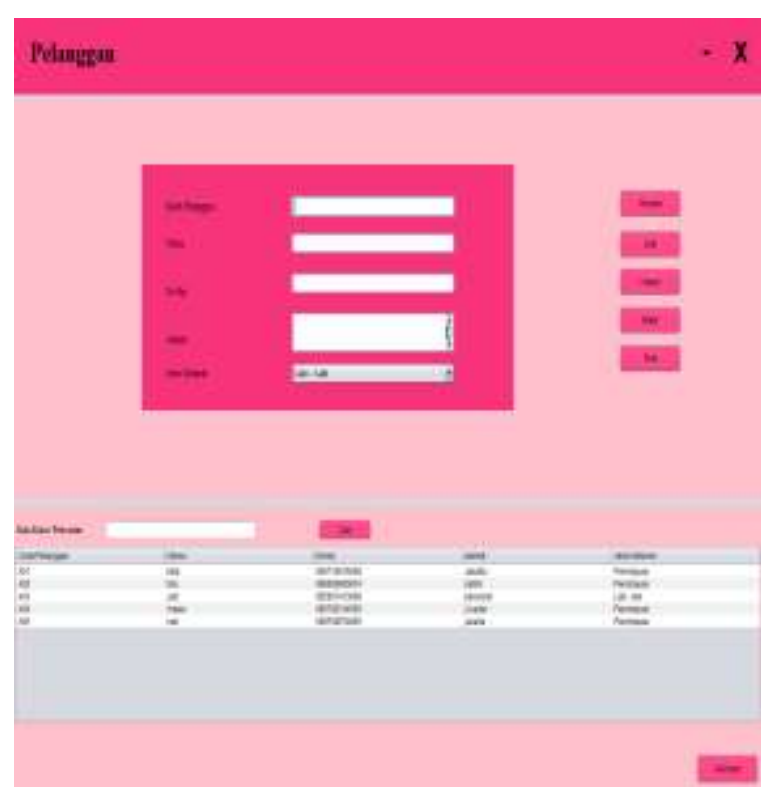

Gambar 4. From Pelanggan

Pada tampilan diatas merupakan tampilan data pelanggan guna untuk menginput data pelanggan, dalam form tersebut juga bisa untuk menghapus atau mengedit data pelanggan jika terjadi kesalahan saat menginput data, data tersebut di simpan dalam database. jika terdapat banyak pelanggam dan kesusahan dalam mencari salah satu pelanggan tertentu juga terdapat kolom cari bisa menggunakan kata kunci kode pelanggan.

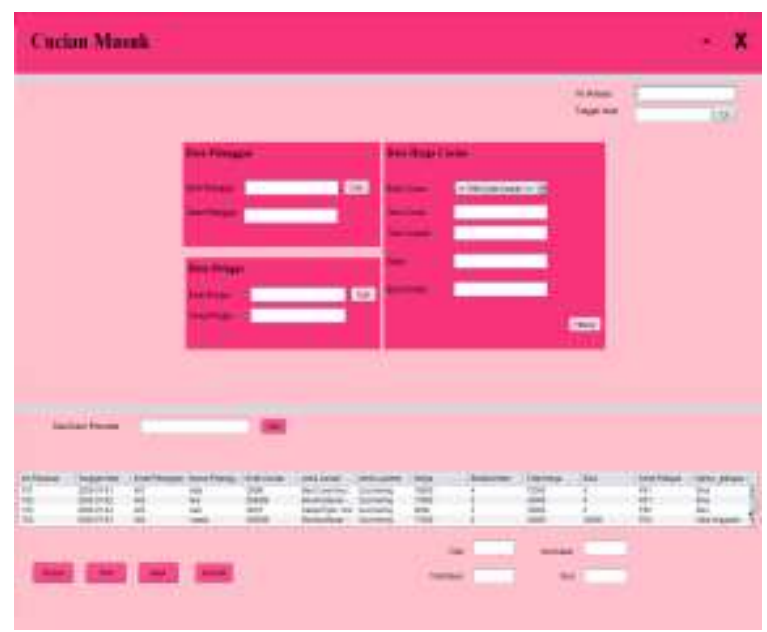

Gambar 5. Form Cucian Masuk

Tampilan diatas merupakan form transaksi antara pelanggan dan petugas. Awal transaksi dengan input no pesanan dan tanggal antar, pada kolom data pelanggan terdapat kolom kode pelanggan input kode pelanggan dan klik cari dan keluar otomatis nama pelanggan begitu juga pada kolom petugas. Pada kolom harga cucian terdapat dropdown kode cucian dan otomatis keluar jenis cucian, layanan, harga dan petugas hanya perlu input berat/jumlah cucian yang di bawa pelanggan, petugas dapat klik hitung dan keluar lah total harga jika pelanggan ingin bayar sekarang juga terdapat kolom kembalian jika pelanggan membayar dengan uang lebih dan jika pelanggan membayar dengan uang yang kurang terdapat keterangan sisa biaya yang harus di bayar dapat di bayar saat pengambilan cucian, setelah selesai klik simpan dan data akan tersimpan dalam database. Petugas juga dapat print kuitansi untuk tanda bukti transaksi kepada pelanggan.

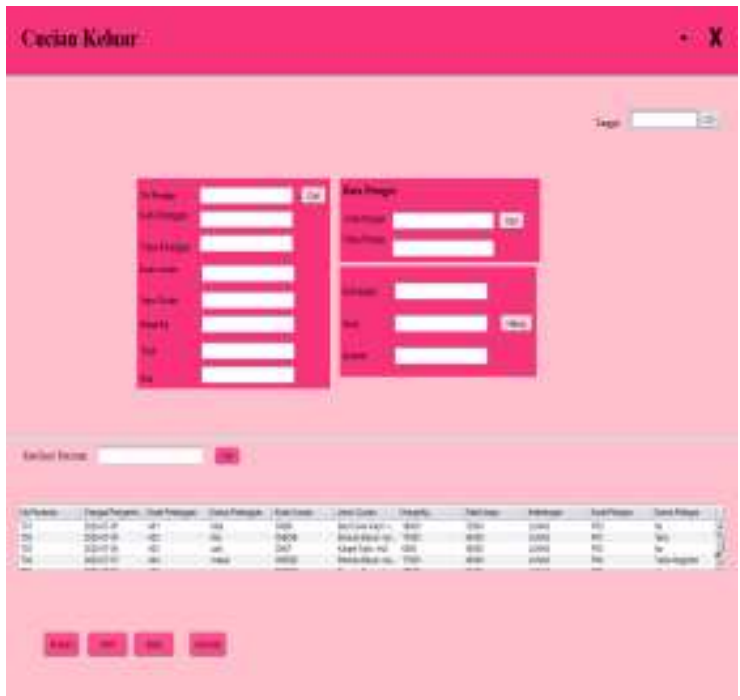

Gambar 6. Form Cucian Keluar

Pada saat pelanggan ingin mengambil cucian menggunakan form di atas petugas memasukan tanggal pengambilan, dan No pesanan lalu klik cari dan keluar semua data pesanan sampai sisa tagihan. Pada kolom petugas diisi dengan data petugas yang melayani saat itu dan setelah selesai tulias keterangan bahwa pelanggan sudah menganbil atau membayar sisa tagihan cucian, terdapat kakulator di atas untuk menghitung jika pelanggan melunasi sisa tagihan untuk memudahkan pegawai dalam menghitung kembalian, lalu klik simpan dan data tersimpan dalam database. 


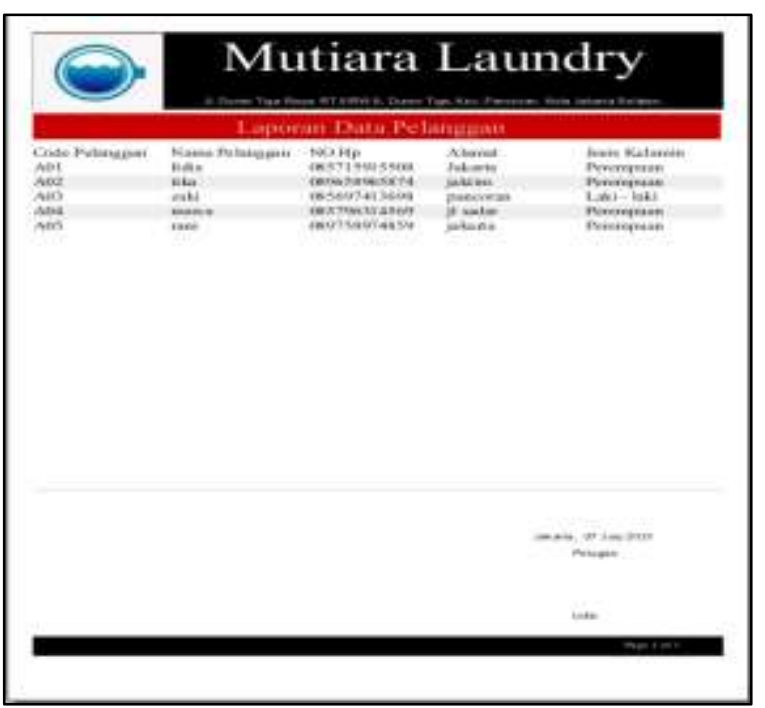

Gambar 7. Laporan Pelanggan

Pada laporan pelanggan terdapat kode pelanggan, nama pelanggan, no hp, alamat dan jenis kelamin pelanggan yang pernah bertransaksi pada Mutiara Laundry.

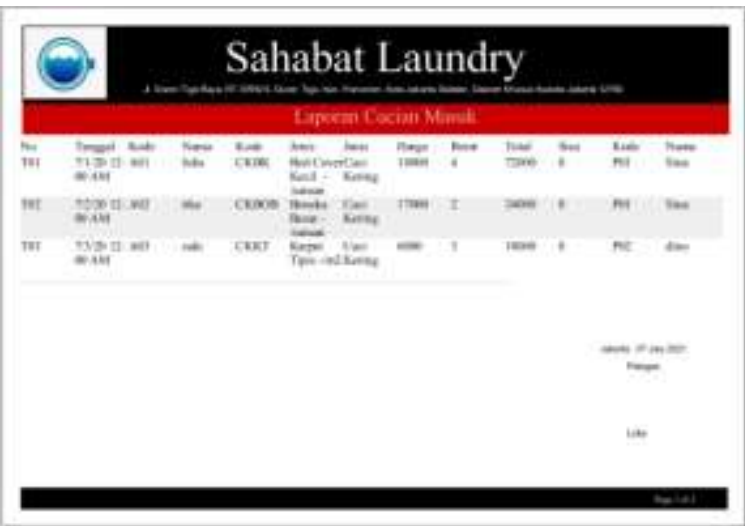

Gambar 8. Laporan Cucian Masuk

Berikut adalah laporan cucian masuk. Tujuannya untuk mengetahui berapa banyak jumlah cucian masuk pada Mutiara Laundry. Sedangkan untuk laporan cucian keluar ditunjukkan pada gambar 9 di bawah ini.

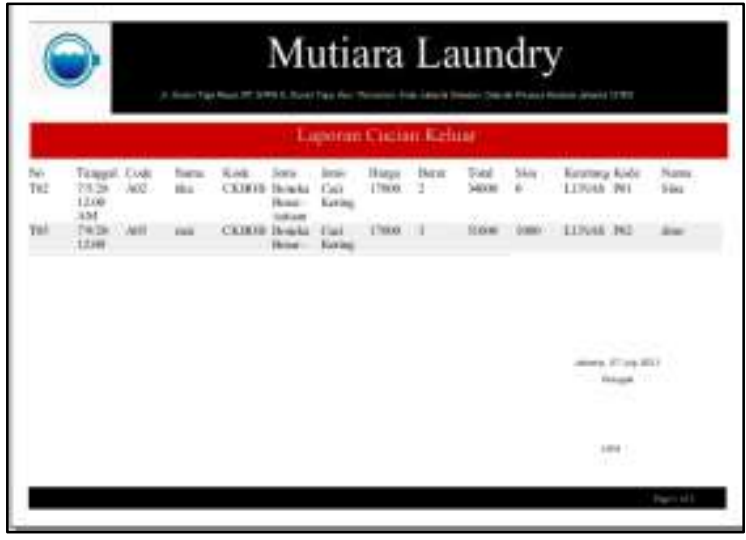

Gambar 9. Laporan Cucian Keluar

Berikut adalah hasil pengujian sistem dengan black box testing.

Tabel 1. Hasil Pengujian Sistem

\begin{tabular}{|c|c|c|c|}
\hline Nama & Skenario Pengujian & $\begin{array}{l}\text { Hasil } \\
\text { yang } \\
\text { dihar } \\
\text { apkan }\end{array}$ & Hasil \\
\hline $\begin{array}{l}\text { Pelang } \\
\text { gan }\end{array}$ & $\begin{array}{l}\text { Mengisi } r \text { Kode } \\
\text { Pelanggan,nama, No } \\
\text { Hp, Alamat, Jenis } \\
\text { Kelamin }\end{array}$ & $\begin{array}{l}\text { Sistem } \\
\text { akan } \\
\text { mener } \\
\text { ima }\end{array}$ & Berhasil \\
\hline $\begin{array}{l}\text { Cucian } \\
\text { Masuk }\end{array}$ & $\begin{array}{l}\text { Mengisi No } \\
\text { Pesanan, Tanggal } \\
\text { Antar, Id } \\
\text { pelanggan, Nama } \\
\text { Pelanggan, Kode } \\
\text { Cucian, Jenis } \\
\text { Cucian, Janis } \\
\text { Layanan, Harga, Berat } \\
\text { Cucian, Total } \\
\text { Harga, Sisa } \\
\text { Tagihan, Id } \\
\text { Petugas, Nama } \\
\text { Petugas }\end{array}$ & $\begin{array}{l}\text { Sistem } \\
\text { akan } \\
\text { mener } \\
\text { ima }\end{array}$ & Berhasil \\
\hline $\begin{array}{l}\text { Cucian } \\
\text { Keluar }\end{array}$ & $\begin{array}{l}\text { Mengisi No } \\
\text { Pesanan, Tanggal } \\
\text { Pengambilan, Id } \\
\text { pelanggan, Nama } \\
\text { Pelanggan, Kode } \\
\text { Cucian, Jenis } \\
\text { Cucian, Janis } \\
\text { Layanan, Harga, Berat } \\
\text { Cucian, Total } \\
\text { Harga, Keterangan } \\
\text { Status Cucian, Id } \\
\text { Petugas, Nama } \\
\text { Petugas }\end{array}$ & $\begin{array}{l}\text { Sistem } \\
\text { akan } \\
\text { mener } \\
\text { ima }\end{array}$ & Berhasil \\
\hline
\end{tabular}


Berdasarkan black box testing pada Tabel 1 dapat disimpulkan bahwa fungsionalitas aplikasi dapat berjalan sesuai harapan.

\section{SIMPULAN DAN SARAN}

Dengan adanya sistem informasi point of sales berbasis komputer yang berupa program aplikasi ini dapat memudahkan dalam proses transaksi dan pengelolahan data pelanggan, pegawai. Aplikasi ini dapat menunjang efisiensi dan efektifitas kerja, karena dapat memperkecil peluang terjadinya kesalahan pengolahan data yang dibutuhkan dan mempermudah dalam pembuatan laporan. Dengan aplikasi yang sudah disediakan diharapkan dapat menggunakan sistem informasi ini dengan baik dan melakukan beberapa perawatan agar sistem dapat tetap optimal serta dapat mengembangan sistem aplikasi tersebut.

\section{UCAPAN TERIMAKASIH}

Penelitian ini dapat dilaksanakan dengan baik berkat bantuan dari berbagai pihak, untuk itu peneliti mengucapkan terimakasih kepada para pegawai Mutiara Laundry dan Bapak Muhammad Irsyad Gemilang selaku anak pemilik Mutiara Laundry atas kerjasama dan partisipasi dalam penelitian ini.

\section{DAFTAR PUSTAKA}

Afrianto, Y., Ginting, N. B., Suratun, \& Nelawati, Y. (2020). Sistem Informasi Inventory P.O.S (POINT OF SALES) Berbasis Web pada Counter Celular. JURTEKSI, 126.

Chandra, H. K. (2019). Pengantar Teknologi Informasi. Poliban Press.

Fitri, R. (2020). Pemrograman Basis Data Menggunakan MySQL. Poliban Press Anggota APPTI.

Hamidin, D., \& Maniah. (2017). Analisis dan Perancangan Sistem Informasi. Budi Utama.

Manik, V., \& Nusantara, I. B. (2019). Aplikasi Pelayanan Jasa Pada Laundry Berbasis Android Untuk. Jurnal Manajemen Bisnis, 22(1), 82-91.
Nofriadi. (2018). Java Fundamental dengan Netbeans 8.0.2. Budi Utama.

Putra, N. (2015). Research \& Development Penelitian dan. Raja Grafindo Persada.

Rusli, M., Rinartha, I. K., \& Atmojo, Y. P. (2016). Belajar Pemrograman Java Dengan Netbean. Andi Offset.

Sidharta, I., \& Wati, M. (2015). Perancangan dan implementasi sistem informasi urunan desa (URDES) berdasarkan pada pajak bumi dan bangunan. Jurnal Computech \& Bisnis, 9, 105.

Sugiyono. (2016). Metode Penelitian Kuantitatif, Kualitatif dan $R \& D$. Alfabeta. 